\title{
Using Doppler Radar with a Simple Explicit Microphysics Model to Diagnose Problems with Ice Sublimation Depth Scales in Forecast Models
}

\author{
Jonathan M. Wilkinson*, Robin J. Hogan, Anthony J. Illingworth \\ Department of Meteorology, PO Box 243, Earley Gate, Reading, Berkshire, RG6 6BB, UK
}

\begin{abstract}
Several previous studies have attempted to assess the sublimation depth scales of ice particles from clouds into clear air. Upon examining the sublimation depth scales in the Met Office Unified model (MetUM), it was found that the MetUM has evaporation depth scales of 2-3 times that of radar observations. Similar results can be seen in the ECMWF, RACMO and MétéoFrance models. In this study, we use radar simulation (converting model variables into radar observations) and 1-dimensional explicit microphysics numerical modelling to test and diagnose the cause of the deep sublimation depth scales in the forecast model. The MetUM data and parametrization scheme is used to predict terminal velocity, which can be compared to the observed Doppler velocity. This can then be used to test the hypothesis for why the sublimation depth scale is too large within the MetUM. Turbulence could lead to dry air entrainment and higher evaporation rates; particle density may be wrong, particle capacitance may be too high and lead to incorrect evaporation rates or the humidity within the sublimating layer may be incorrectly represented. We show that the most likely cause of the deep sublimation zones is the incorrect representation of model humidity in the layer. This is tested further by using a 1-dimensional explicit microphysics model, which tests the sensitivity of ice sublimation to key atmospheric variables and is capable of including sonde and radar measurements to simulate real cases. Results suggest that the MetUM grid resolution at ice cloud altitudes is not sufficient enough to maintain the sharp drop in humidity that is observed in the sublimation zone. Copyright (c) 2009 Royal Meteorological Society
\end{abstract}

KEY WORDS Ice Clouds, Cirrus, Unified Model, Ice Evaporation, Bulk Microphysics, Microphysical Parametrizations, Model cloud evaluation

Received 16 March 2010; Revised ??? ; Accepted ???

\section{Introduction}

Clouds are an important constituent of the climate system (Arking, 1991; Quante, 2004) and are one of the major uncertainties in general circulation model forecasts of future climate. The representation of ice clouds in operational weather and climate models is not only crucial to radiative transfer (e.g. Stephens et al., 1990; Senior and Mitchell, 1993; Lohmann and Roeckner, 1995), but can have several implications for both the dynamics and the thermodynamics of the model. Clough and Franks (1991) and Clough et al. (2000) showed that the dynamics of operational models can be altered significantly by the evaporation of ice beneath clouds.

Using simple numerical models, several previous researchers (Hall and Pruppacher, 1976; Harris, 1977; Heymsfield and Donner, 1990; Clough and Franks, 1991) have established a mean depth scale of sublimation from ice to vapour within ice clouds. They all suggested that due to the low bulk density and fall velocity the sublimation should, in theory, take place in a shallow layer, of the order of a few hundred metres in depth.

${ }^{*}$ Correspondence to: $\operatorname{Dr}$ J. M. Wilkinson (Present address), Met Office, FitzRoy Road, Exeter, EX1 3PB UK; email: jonathan.wilkinson@metoffice.gov.uk
Forbes and Hogan (2006), (hereafter FH06) used cloud radar to estimate the sublimation depths of particles beneath approaching warm fronts. They found that, on average, the ice water content decreased from its maximum value to $10 \%$ of the maximum in a depth of around $500 \mathrm{~m}$, with no evaporation layer greater than a depth of $1 \mathrm{~km}$. When they examined data from the Met Office Unified Model (hereafter MetUM) they observed that this "evaporation zone" was 2 to 3 times the depth shown in the observations. The mis-representation of this layer means that the MetUM does not accurately represent the cooling around the base of the ice clouds (of order $1 \mathrm{~K}$ hour $^{-1}$ ). FH06 then showed that this can lead to the front developing incorrectly within the model. This can eventually lead to the incorrect position of the front and its associated rainbands. Wilkinson (2007) extended FH06 to other operational models from the Cloudnet programme (See Illingworth et al., 2007 for model details). The models used were the prognostic ECMWF model and the KNMI regional atmosphere climate model (RACMO); and the diagnostic Météo-France model. Wilkinson's analysis found that all the model studied suffered from the same exaggerated evaporation depth zone as shown in table I. The prognostic models overestimate the depth of the evaporating layer, which implies that the deeper-than-observed evaporation zone is not unique 
to the MetUM. Also of interest is the large standard deviation of the evaporation zones for the prognostic models, which implies that different situations affect the rate of evaporation. It should also be noted that although the diagnostic Météo-France model has a lower depth factor, Illingworth et al. (2007) show that it has difficulty in expressing accurate amounts of ice water content at the time of study.

FH06 suggested several candidates that may cause the poor representation of this layer in the MetUM:

(i) The MetUM vertical grid resolution may be too low at ice cloud altitudes, and so does not allow for a sharp decrease in prognostic variables such as ice water content.

(ii) The relative humidity in the MetUM may be too great beneath the evaporating ice cloud.

(iii) The MetUM's ice particle terminal fall speed may be too high.

(iv) The numerics in the MetUM may be too diffusive.

(v) The Parametrized ice evaporation rate may be too low. Although the input variables of temperature and humidity may be correct, the equations used to represent evaporation may be wrong.

In addition, two further possible candidates can be identified:

(vi) The MetUM does not account for rapid turbulence within the sublimation region which could entrain dry air and increase evaporation rates.

(vii) There is evidence (Westbrook et al., 2008) that the capacitance term used by numerical models may be incorrect for aggregates, which are the dominant particle type in the evaporating layer.

Given that several models are shown by Wilkinson (2007) to suffer from the same problem, the hypotheses suggested for the MetUM can be extended to all the forecast models, however, it should be noted that it may not be a common problem that is causing the deeper-thanobserved evaporation zone in the models.

Since the period of study described in FH06, the 94- $\mathrm{GHz}$ radar at Chilbolton has been updated to measure the vertical Doppler velocity, which can be used to examine the fall velocity of the evaporating ice crystals and the standard deviation of mean Doppler velocity, from which the turbulent kinetic energy dissipation rate can be inferred, using the method of Bouniol et al. (2003). The latter is one of several cloud products that have now become available as part of the Cloudnet project (Illingworth et al., 2007), which includes other relevant properties of clouds such as ice water content.

In this paper, we examine each of the hypotheses (i) to (vii) in turn, using Doppler radar observations. To do this, we shall simulate the Doppler velocity observed by the radar using MetUM variables and parametrizations. Most studies (e.g. Illingworth et al., 2007) derive model variables from radar observations, but this technique is useful as it allows the prediction of the radar Doppler fall velocity from the model and hypothesis (iii) to be tested.

Section 2 illustrates the data used in this study and describes the methodology. Section 3 examines and rejects some of the hypotheses using Doppler radar simulation. Section 4 focuses on the humidity hypotheses. In order to fully identify the cause, some 1-dimensional explicit microphysics modelling is done in section 5. Conclusions are drawn in section 6 .

\section{Data and Methodology}

\subsection{4-GHz Radar Data}

The instrument used for this study is the verticallypointing 94-GHz radar at the Chilbolton Observatory in Hampshire. Since July 2001, it has been able to measure Doppler parameters in addition to the standard radar reflectivity $(Z)$. It operated continuously (apart from short periods of occasional maintenance) between January 2003 and March 2004, and thus provides a long data set of the presence and microphysical properties of ice cloud; the data for this study are taken from this period. The three parameters used in this study are $Z$, Doppler velocity $\left(V_{\text {Dop }}\right)$, which is a measure of the reflectivity-weighted vertical velocity of the ice particles as they fall from the cloud; and standard deviation of mean Doppler velocity $\left(\sigma_{\overline{\mathrm{v}}}\right)$. It should be noted that this parameter is different from Doppler Spectral Width (see Bouniol et al., 2003).

\subsection{Met Office Model Data}

The model used in this study is the Met Office Unified Model at $12 \mathrm{~km}$ (mesoscale) resolution. The MetUM time series is generated by taking hourly vertical profiles of the grid boxes that lie above Chilbolton, from 6-11 hour forecasts, initiated four times each day. These hourly snapshots give values of MetUM wind, temperature, relative humidity and ice water content (IWC). The microphysical cloud parametrizations used by Wilson and Ballard (1999) are used to obtain radar reflectivity $(Z)$ and Doppler velocity $V_{\text {Dop }}$ from MetUM data, so that they can be compared with the radar data. This methodology is detailed in appendix I.

\subsection{Selection of Data}

The data were selected subjectively from a variety of cases of evaporating ice from January 2003 to March 2004. The following criteria were applied to the radar and MetUM data:

(i) Ice data only. The temperature at cloud base in each ice water content profile should remain below $0^{\circ} \mathrm{C}$ so that any ice is evaporating rather than melting. Mixed-phase cloud is also rejected using data from the Chilbolton 905-nm lidar ceilometer to locate the presence of liquid water in the radar data, as in Hogan et al. (2003b) 


\begin{tabular}{|c|c|c|c|c|c|}
\hline Model & $\begin{array}{c}\text { Cloud } \\
\text { Ice Variable } \\
\text { Treatment }\end{array}$ & $\begin{array}{c}\text { Vertical Grid } \\
\text { Resolution } \\
\text { at } 5 \mathrm{~km}\end{array}$ & $\begin{array}{c}\text { Mean } \\
\text { Evaporation } \\
\text { Zone Depth }\end{array}$ & $\begin{array}{c}\text { Standard } \\
\text { Deviation of } \\
\text { Evaporation } \\
\text { Zone Depth }\end{array}$ & $\begin{array}{c}\text { Depth } \\
\text { Factor }\end{array}$ \\
\hline Met Office & Prognostic & $615 \mathrm{~m}$ & $1614 \mathrm{~m}$ & $630 \mathrm{~m}$ & 2.55 \\
ECMWF & Prognostic & $529 \mathrm{~m}$ & $1334 \mathrm{~m}$ & $865 \mathrm{~m}$ & 2.10 \\
Météo-France & Diagnostic & $502 \mathrm{~m}$ & $912 \mathrm{~m}$ & $452 \mathrm{~m}$ & 1.44 \\
RACMO & Prognostic & $532 \mathrm{~m}$ & $1317 \mathrm{~m}$ & $714 \mathrm{~m}$ & 2.08 \\
\hline
\end{tabular}

Table I. Summary of evaporation zone depths, cloud schemes and grid resolution from four Cloudnet models, taken from Wilkinson (2007). The depth factor is the ratio of model and radar mean evaporation zone depths, so a depth factor of two would imply that the mean model evaporation zone depth is twice the radar observations.

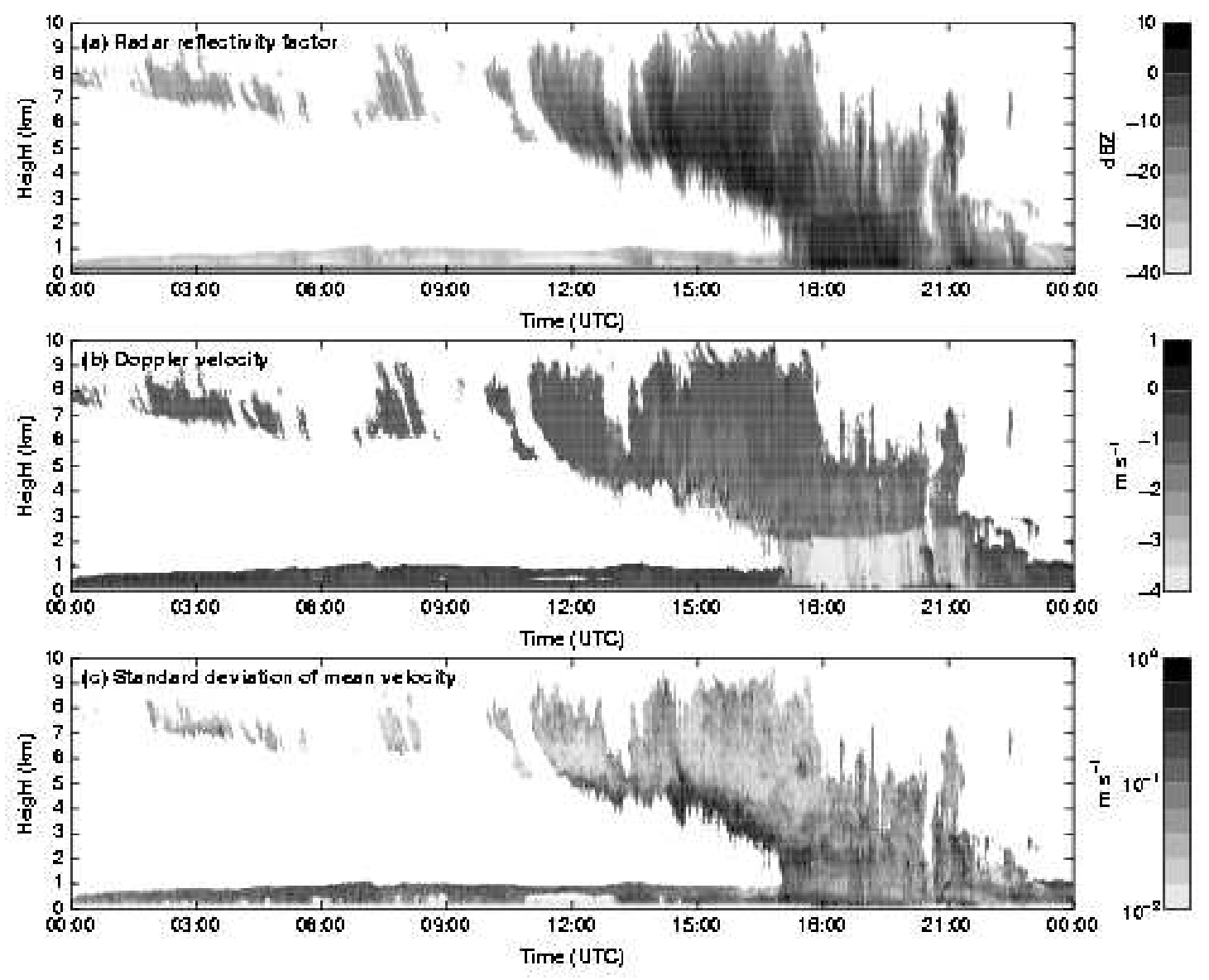

Figure 1. Radar variables observed above Chilbolton on 23 January 2004. In this case, they show a typical case of evaporating ice beneath an approaching warm front. (a) Radar reflectivity, (b) Doppler velocity. The high velocity in the rain beneath the front can easily be seen and contrasted with the lower values in the ice clouds. (c) Standard deviation of mean Doppler velocity, which can be used to infer the turbulence of the air.

(ii) In order to obtain a high enough ice water content for a sensible evaporation measurement to be obtained, the duration of the ice clouds had to be for at least 2 hours and the clouds had to be at least 2 $\mathrm{km}$ thick in the vertical.

(iii) Absence of Rain. Any hours that contained any rain amongst the ice data were rejected, even if there was ice present above the falling rain. This is for two reasons. Firstly, the presence of rain suggests melting, rather than evaporation is taking place.
This is the case after 17.00 UTC in the example shown in figure 1 . Secondly, in a few cases, some shallow convective cloud was found to be raining beneath and separate from the evaporating fronal ice cloud above. This data was still removed from the study as the radar signal can be severely attenuated in rain by attenuation (Lhermitte, 1990) and by rain lying on wet radomes (Hogan et al., 2003a).

The depth of the evaporation zone was defined by the same method as FH06. The evaporation zone is said to be the 
region between the maximum IWC in a profile and the height below where the IWC had decreased to $10 \%$ of this maximum (i.e. $90 \%$ of the ice had evaporated from the profile).

To compare radar data, (which has a 30-s time resolution and $60 \mathrm{~m}$ vertical resolution), with MetUM data, (which has a one hour time resolution and a vertical resolution that varies from $500 \mathrm{~m}$ to $750 \mathrm{~m}$ in the midtroposphere), is rather difficult due to the large resolution difference between the two grids. Also, performing long temporal averages through sloping ice cloud (such as that in figure 1) may causes problems. An average at constant height may include clear air ahead of the ice cloud and as the cloud base descends, the calculation may also include the mid-cloud or clear air above the cloud as well as the cloud base and evaporation zone we are interested in studying.

To solve these problems, the radar and MetUM data are put on the same grid, with the top of each evaporation zone set at the same altitude. This is done as follows:

1. The radar data (reflectivity, IWC and Doppler velocity) are averaged to a one-hour resolution, consisting of 120 radar profiles of 30 seconds duration. The vertical grid resolution remains the same. This horizontal averaging removes some of the effects of updraughts and downdraughts on the vertical velocity within the cloud. All radar reflectivity is linearly averaged and the Doppler velocity average is reflectivity-weighted.

2. The MetUM data are linearly interpolated on to the radar height grid.

3. The profiles of both radar and MetUM are adjusted vertically to account for any slope in the ice cloud. This is done by finding the height of the maximum reflectivity value in each hourly radar or MetUM profile and shifting it up or down, so that the maximum value occurs at an adjusted altitude $\left(z_{a d j}\right)$ of zero.

The entire process is shown in figure 2. In our comparisons, we also adjust quantities other than radar reflectivity (e.g. Doppler Velocity or standard deviation of mean Doppler velocity). In these cases, to ensure all the data lie on the same grid, any adjusting is still done relative to the maximum value of reflectivity for each profile; adjusting each quantity to its maximum value would cause a bias in the results.

Once this procedure is complete, it is possible to time-average the entire data set and produce a profile of the mean radar reflectivity and fall velocities versus height relative to the peak in $Z, Z_{a d j}$.

\section{Hypothesis Testing}

A total of 89 hours of evaporating ice were selected from cases over the period from January 2003 to March 2004. From these data, some of the hypotheses suggested by FH06 and Wilkinson (2007) could be tested. Many candidates were tested and rejected as follows:
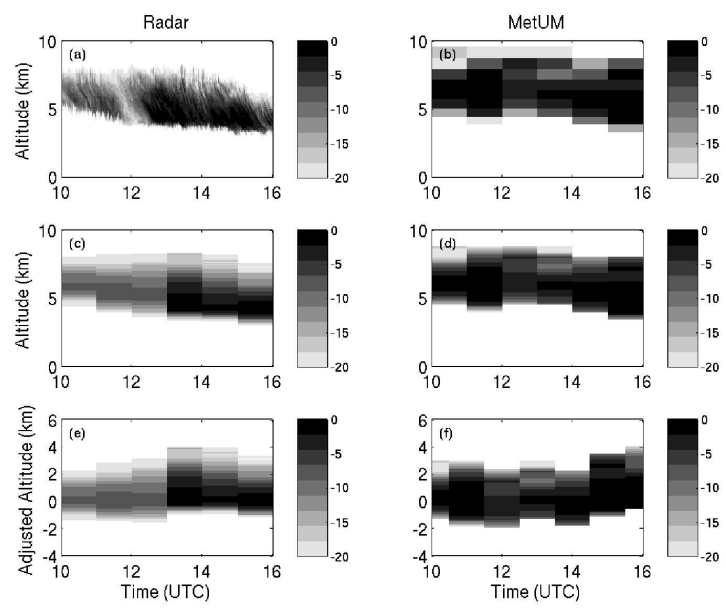

Figure 2. Transformation of radar and MetUM reflectivity $(Z)$ data from 4 March 2004 to allow fair comparison. Radar data are shown in the left column (a, c and e), MetUM data on the right (b, d and f). The raw data are on the top row ( $\mathrm{a}$ and $\mathrm{b}$ ). The centre row shows the result of averaging the radar data to a 1-hour resolution (c), while the MetUM data have been interpolated to the radar height grid (d). The bottom row shows the result of the adjusting of both data sets such that each profile has its maximum $Z$ at a $z_{a d j}$ of zero.

\subsection{Particle Terminal Velocity}

Figure 3 shows a comparison between the radar and MetUM reflectivity $(Z)$, and between the Doppler fall velocity $\left(V_{\text {Dop }}\right)$ obtained from radar measurements with the $Z$-weighted fall velocity obtained from the model parametrization. It can be seen that the values of $Z$ from the MetUM are about $3 \mathrm{dBZ}$ too large above $Z_{a d j}$ of zero. This could be due to the MetUM density function being too large, which will be examined more rigorously in section 3.3 .

Comparing the MetUM Parametrized fall velocity with the observed Doppler velocity is trickier as the radar Doppler fall velocity is a sum of the vertical air velocity $\left(v_{a}\right)$, and the Z-weighted mean ice particle terminal fall velocity $\left(v_{t}\right)$.The air velocity within ice clouds can vary from a few $\mathrm{cm} \mathrm{s}^{-1}$ to a couple of metres per second, although this latter value is very rare. A typical ice particle terminal fall velocity is on the order of $1 \mathrm{~m} \mathrm{~s}^{-1}$. It is therefore possible that the vertical velocities observed could be influenced by the presence of updraughts and downdraughts in the data. Within the middle of the cloud, the hourly-mean Doppler velocity will include the contribution from updraughts and downdraughts, although these contributions are likely to be very small due to the averaging and hence $\overline{v_{a}} \ll \bar{v}_{t}$.

However, around the cloud base, the air generally becomes more turbulent. This is apparent in the standard deviation of mean Doppler velocity, shown in figure 1(c). Here, the contribution from updraughts and downdraughts is likely to be larger and the hourly-averaged Doppler velocity may include a significant period of data where the vertical air velocity is either an updraught or a downdraught. This is especially of relevance where at the base 

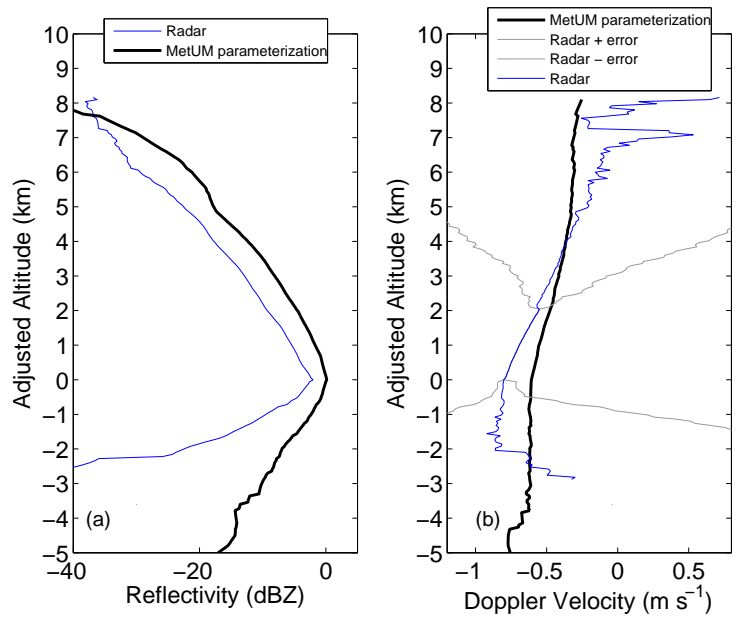

Figure 3. Profiles of (a) radar reflectivity, $Z$ and (b) Doppler fall velocity, $V_{\text {Dop }}$ averaged over 89 hours. The grey lines on the Doppler velocity plot give an estimate of the error on the radar fall velocity due to preferential sampling of updraughts and downdraughts throughout the cloud (see text for details).

of the cloud, the averaging includes a large portion of clear air (i.e. where the radar data pixel shows no cloud). In these regions we cannot tell whether the air is ascending, or descending and at what rate.

To ascertain the effect of the updraughts and downdraughts on the results, before the averaging process we can allocate each cloud-free radar pixel with an updraught of $2 \mathrm{~ms}^{-1}$ and then with a downdraught of $2 \mathrm{~ms}^{-1}$, which is assumed to be the maximum velocity we would ever observe within a frontal ice cloud. This is used to produce the thin grey lines on figure 3(b). Where these lines agree with the MetUM velocity, we are confident that the error on the updraughts and downdraughts is small, but where the lines diverge, we are less confident of the result.

In order to test the ice particle parametrization, we will compare the radar $V_{\text {Dop }}$ with the MetUM Parametrized velocity within the middle of the cloud (by definition only cases greater than $2 \mathrm{~km}$ thick and with $100 \%$ cloud cover in the radar) and where the effect of the air velocity is assumed to be small. We then assume that the results will also be valid for the evaporation zone, where the spread of vertical air velocities are larger. However, in the MetUM microphysics scheme the assumptions make no distinction between middle or edge of cloud and hence this result should be valid.

The key result that is shown in figure 3(b) is that within the mid-cloud region, the MetUM crystal fall velocity is $30 \%$ lower than the Doppler fall velocity $\left(V_{\text {Dop }}\right)$ measured by the radar. This agrees with ARM data evaluated for a temperature of $230 \mathrm{~K}$ and different ice water contents by Deng and Mace (2008).

In order to see how well the MetUM parametrization performs with different particle sizes, the velocity values have been plotted against the reflectivity values. Due to the large amount of data, the fall velocities have been binned into 1-dBZ bins, with the mean, standard deviation and range of the data shown. Figure 4 shows the results for the middle of the cloud, and the results for the evaporation zone. In the middle of the cloud, it can be seen that for low values of $Z$ (small particles), the MetUM accurately predicts the observed values of $V_{\text {Dop }}$. Above $Z$ values of $-15 \mathrm{dBZ}$, the MetUM $V_{\text {Dop }}$ is up to $50 \%$ less than those observed by the radar. Thus, the difference in radar and MetUM fall velocity above $z_{a d j}=0$ in figure 3 appears to be entirely due to the MetUM poorly representing the larger particles.

Looking at figure $4 \mathrm{~b}$, which shows the comparison between MetUM and radar fall velocities in the evaporation zone, it can be seen that the radar fall velocities are always appreciably greater than the MetUM values. This is due to the preferential sampling of downdraughts when averaging radar data to a one hour horizontal resolution.

From the comparison made for the middle of the cloud, it appears that the MetUM parametrization is able to representing the mean radar $V_{\text {Dop }}$ to within $0.3 \mathrm{~ms}^{-1}$. If one assumes it behaves in the same way within the evaporation zone before the effects of the vertical air velocity were included, then it would appear that the MetUM does not have the ice particles falling out too fast. In fact, as can be seen in figures $3 \& 4$ the MetUM parametrization generally has the ice particles falling out too slowly. FH06 suggested that the evaporation zone depth would scale linearly with ice particle fall velocityso to have an evaporation zone in the MetUM with a depth of 2-3 times that in the radar data, a MetUM ice particle fall velocity of 2-3 times the radar fall velocity would be required. Even with a strong downdraught present in the radar data shown on the right hand plot in figure 4, there is no way that a velocity of 2-3 times the radar fall velocity could occur. It is very unlikely that large-scale updraughts and downdraughts in ice cloud would be larger than $20 \mathrm{~cm}$ $\mathrm{s}^{-1}$, so the MetUM Parametrized particle fall velocity can be ruled out as the reason for the deep evaporation zone within the MetUM. So one can conclude that some other factor than fall velocity is causing the error in the depth of the evaporation zone.

\subsection{Turbulence in the Evaporation Zone}

In section 1, one of the hypotheses proposed to explain the deeper evaporation zone depth in the MetUM is due to the MetUM not accounting for the increased evaporation rate caused by vigorous turbulence generated by the ice particles evaporating as they fall from the ice cloud into the dry air beneath. The idea is that in cases of increased turbulence at the cloud base, the evaporation rate would increase significantly due to increased ventilation and entrainment of dry air around the ice particles. Since the MetUM does not account for any turbulence above the boundary layer, this may be the cause of the deeper evaporation zone in the MetUM.

Measurements of the turbulent kinetic energy (TKE) dissipation rate $(\epsilon)$ have been estimated from radar observations of the standard deviation of mean Doppler velocity 

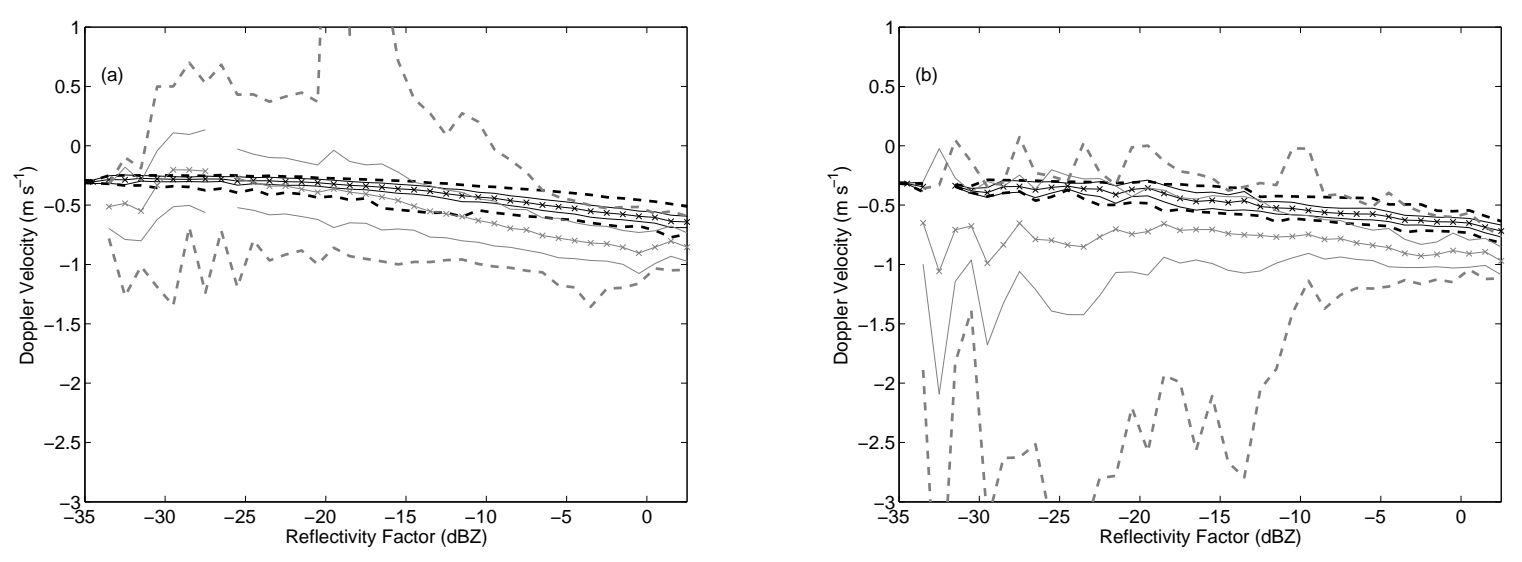

Figure 4. Hourly averaged radar reflectivity and Doppler velocity for (a) the middle of the cloud and (b) the evaporation zone. In each plot, radar data are shown in grey and MetUM data in black. The crossed line in each case is the mean Doppler velocity, the solid lines indicate one standard deviation about the mean, while the dashed lines indicate the range of the data.

$\left(\sigma_{\overline{\mathrm{v}}}\right)$, according to the method described by Bouniol et al. (2003). The maximum value of $\epsilon$ in each profile has been plotted against the depth of the evaporation zone for both radar and MetUM data. If the mis-representation of turbulence is the cause of the deeper evaporation zone in the MetUM, then we should see a decrease in the radar evaporation zone depth as $\epsilon$ increases, but no change in the MetUM evaporation zone depth with $\epsilon$. Figure 5 shows the plot of maximum $\epsilon$ in each hourly averaged profile against evaporation zone depth for the 89 hours of study. In the vast majority of the cases shown in figure 5, the MetUM evaporation zone depth is much greater than the radar. However, there is no change in radar evaporation zone depth as turbulence increases, which means that the amount of turbulence does not affect the evaporation depth scales of the ice. Thus, it can be concluded that the absence of turbulence in the MetUM cloud parametrization scheme is not the cause of the deeper evaporation zone within the MetUM.

\subsection{Particle Density and Terminal Velocity}

In section 1, it was also hypothesised that the MetUM's deeper evaporation zone could be due to the MetUM parametrization scheme having an incorrect density function, which would affect the parameterised fall velocity and thus increase the evaporation zone depth. Currently the function used is given in (3) in appendix I. This is roughly a factor of 4 greater than the Brown and Francis (1995) density (which when expressed in units of $\mathrm{kg} \mathrm{m}^{-3}$ is $\rho=0.0354 D^{-1.1}$ ).

In order to test whether incorrect parameterised ice particle density is the cause of the deeper evaporation zone in the MetUM, a sensitivity test on the data set was performed. The current parametrization, given in (3) was altered as follows. First, the value of the 0.13 constant was doubled and halved to form two new relationships:

$$
\rho=0.26 D^{-1}
$$

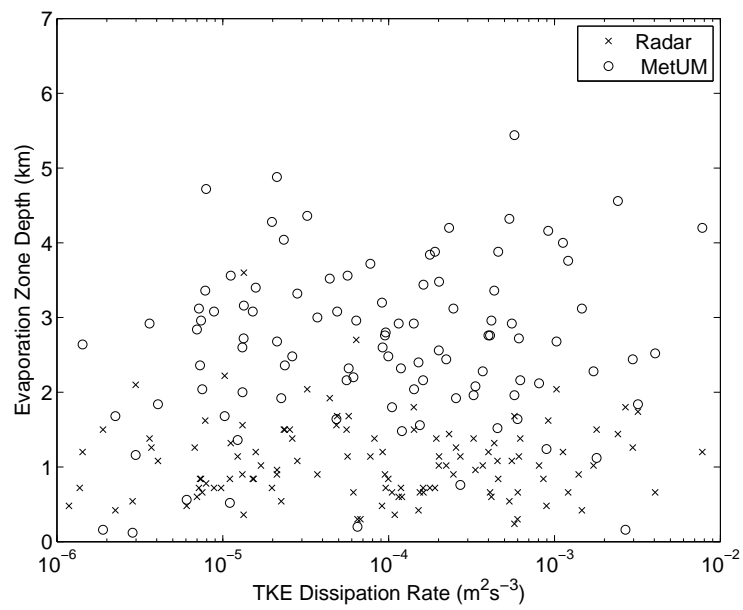

Figure 5. Hourly-averaged evaporation zone depth scales in each profile for the MetUM and radar against maximum observed hourlyaveraged turbulent kinetic energy dissipation rate, $(\epsilon)$.

$$
\rho=0.065 D^{-1} .
$$

The results for both tests described above are shown in figure 6. Equation 4 relates ice water content to particle mass, and therefore density. To completely test whether the evaporation zone depth would be affected by changes in density, we would need to re-run the MetUM and allow the density to affect the ice water content. However, the results do show how changing the particle density alters the parameterised fall velocity and the MetUM reflectivity values. As these tests have not re-run the MetUM, there was no detectable change in evaporation zone depth in any of the tests.

Looking back at figure 3, which shows the run with the original MetUM density $\left(\rho=0.13 D^{-1}\right)$, it can be 

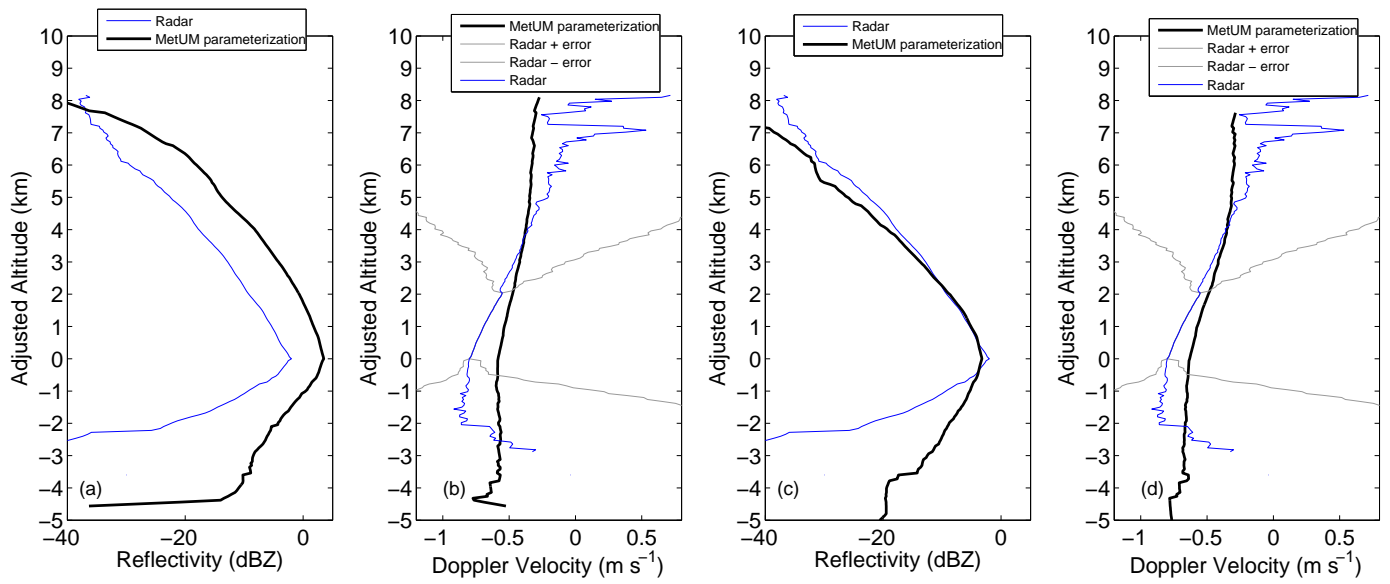

Figure 6. Profiles of $Z$ and $V_{\text {Dop }}$ when the density in the Met Office MetUM is doubled (a,b) and halved (c,d). The labelling is the same as in figure 3 .

seen that the reflectivity values predicted with the MetUM parametrizations are too high by about $3 \mathrm{~dB}$. This means that the MetUM IWC is also too large due to the density function being too large. When the density function in the MetUM is halved, as shown in figure 6(c) and 6(d), the MetUM and radar reflectivity values agree in the $3 \mathrm{~km}$ above the evaporation zone. Doubling the density function in the MetUM makes the reflectivity $6 \mathrm{~dB}$ too big above the evaporation zone. This means that the density function in the Met Office MetUM is too large, and should be closer to half the value.

Looking now at fall velocity, it can be seen that altering the density in the MetUM parametrization has little effect on the profile of MetUM Doppler velocity. It changes in total by about $10 \%$ between the cases shown in figure 3. Changing the density affects the weighting of the large and small particles towards the contribution in Doppler velocity, and this is not significant enough to make the parameterised Doppler velocity greater than the radar Doppler velocity. Hence the incorrect particle density does not change the parameterised fall velocity enough for it to cause the deep evaporation zone in the MetUM.

\section{Evaporation Rate and Humidity}

So far, several candidates for the increased depth of the evaporation zone have been examined, including ice particle terminal fall velocity, ice particle density and the effects of turbulence. One remaining candidate is the role of humidity. FH06 partially addressed this problem. They studied several sonde profiles through evaporating ice cloud, and found that the MetUM relative humidity was on average $7 \%$ too moist beneath the frontal surface, where the ice particles were evaporating. They also studied several sonde profiles from Larkhill radiosonde station for the time period corresponding to the year-long $94-\mathrm{GHz}$ radar data set at Chilbolton. They found that in some of the individual sonde profiles, the relative humidity dropped sharply beneath the evaporation zone, a change that was not accurately represented by the MetUM, which still had a moist bias beneath the evaporation zone. In this section, we shall investigate these ideas in more depth. In section 4.1, the equations set out in Wilson and Ballard (1999) are used to estimate the evaporation rate beneath the evaporating ice cloud, to see if the MetUM's evaporation rate calculations are correct. In section 4.2, several sonde humidity profiles are studied to try and see how the MetUM represents the drop in humidity beneath the evaporating ice cloud.

\subsection{Comparison Between Radar and MetUM Evapora- tion Rates}

The evaporation rate equation used in the MetUM is (9) in appendix II. It is based on well-established cloud physics and is similar to the forms of Pruppacher and Klett (1997) and Mason (1971). So the increased depth in the evaporation zone should not be caused by an incorrect parameterised of the evaporation rate. However, this does not account for the values of the variables used in (9) being wrong.

To see if the MetUM evaporation rate is correct, it is necessary to compare radar and MetUM evaporation rates. This can be done by studying each hourly average profile of $V_{\text {Dop }}$ and IWC in both the radar data and MetUM output. The flux density in $\mathrm{kg} \mathrm{m}^{-2} \mathrm{~s}^{-1}$ at the top and bottom of the evaporation zone can be estimated by multiplying the radar IWC at the top or bottom of the evaporation zone by the mean radar $V_{\text {Dop }}$ at the same point. The same procedure can then be followed for the data obtained from the MetUM output. The difference in flux between the top and bottom of the evaporation zone can then be divided by the depth of the evaporation zone to give an estimate of layer-mean evaporation rate. The differences in radar and MetUM evaporation rate for the 89 -hour period of study are shown in figure 7 . It should 


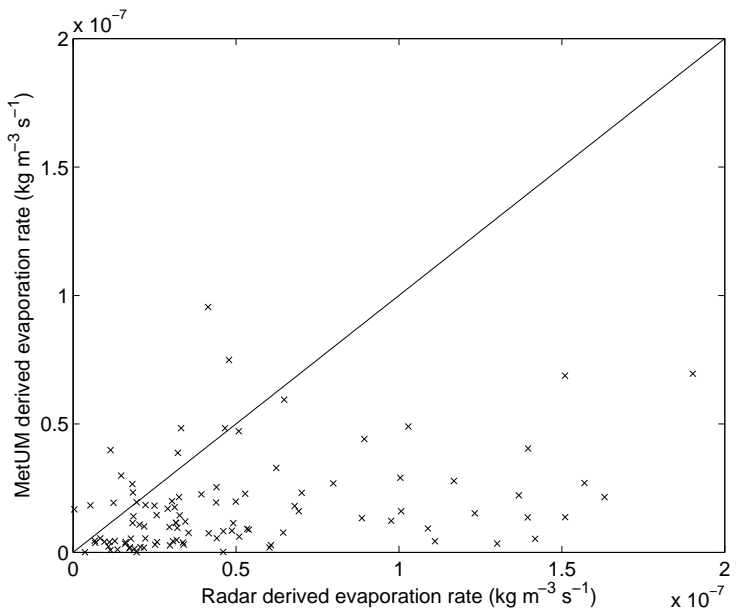

Figure 7. The correlation of the radar layer-mean evaporation rate versus the model's parameterised layer-mean evaporation rate calculated for the MetUM and radar evaporation zones, calculated using the IWC flux density difference and the evaporation zone depth. The solid line is the line $\mathrm{y}=\mathrm{x}$.

be noted that the model velocity used is $V_{\text {Dop }}$ which is Z-weighted. Ideally, we should use the IWC-weighted velocity. However, the two do not differ significantly so use of $V_{\text {Dop }}$ is justified.

Figure 7 shows that the model's layer-mean evaporation rate is only around one third of that derived from the radar data. Looking at (9), we can see that although it is a function of several factors, these can quickly be attributed to changes in four variables. The terms in the denominator are functions of temperature and pressure only. The capacitance term, $C$, is a function of particle diameter only, the supersaturation ratio $\left(S_{i}-1\right)$ is a function of relative humidity only and the ventilation coefficient, $F$ varies with temperature, pressure and particle diameter. Hence the entire equation is a weak function of temperature and pressure, but strongly dependent on particle diameter and relative humidity. This suggests that the either the relative humidity in the equation is wrong, or the Parametrized particle diameter is wrong. If the particle diameter, given in (1) was wrong, then the MetUM would produce incorrect values of reflectivity, IWC and $V_{\text {Dop. }}$. Hence, it appears that humidity gradients within the evaporation zone are the cause of the deep evaporation zone; so we now need to examine how the MetUM represents these gradients.

\subsection{MetUM Representation of Humidity Profiles}

In order to see whether humidity is really the cause of the deeper evaporation zone within the MetUM, profiles from the Larkhill radiosonde, (which is only $25 \mathrm{~km}$ from Chilbolton and therefore can be assumed to be representative of the case studies) were compared with the MetUM profiles of relative humidity. However, there were only a limited number of sonde profiles available at the same time as there were evaporating ice clouds present.
One case that illustrates how the MetUM represents the humidity profile occurred on 4 March 2004. During the day, a thick ice cloud developed, which did not descend to the ground, nor was it part of a system that later produced precipitation at Chilbolton. Figure 8 shows radar and MetUM data around the same time that a sonde was launched from Larkhill (13 UTC).

Two points can immediately be raised from figure 8 . The first is that there is a substantial decrease in IWC at $4 \mathrm{~km}$ predicted by the radar reflectivity values. The peak value in the MetUM is a full order of magnitude less than the radar value. The MetUM does not have high enough values of $Z$ beneath $5 \mathrm{~km}$, caused by the values of IWC being much too low. The gradient of the MetUM IWC is very gentle, taking a couple of kilometers to reduce by $90 \%$. Thus the MetUM has not accurately represented this particular ice cloud.

The second point that can be seen is that the MetUM does not accurately represent the gradient of relative humidity beneath the evaporating ice cloud. The model's peak relative humidity value occurs at $6 \mathrm{~km}$, and it does not decrease to $20 \%$ relative humidity until an altitude of $3 \mathrm{~km}$. The sonde profile shows the relative humidity actually decreasing from $100 \%$ to $20 \%$ in a layer about $200 \mathrm{~m}$ deep, and at an altitude of $4 \mathrm{~km}$, which agrees with the position of the cloud base from the radar measurements. Clough and Franks (1991) suggest using a simple numerical MetUM that the typical evaporation depth scale for ice is of the order of a few hundred metres. The sonde and radar profiles agree with this estimate, but the MetUM does not.

In this case, the MetUM has not correctly represented the IWC and thus the high $Z$ values at the base of the ice cloud. Its humidity and IWC profile shows that the evaporation started too high at $6 \mathrm{~km}$. But does this actually apply to all cases?

It is possible to evaluate the MetUM humidity gradients by comparing them to sonde humidity gradients. During the period of study, all available ascents were found that coincided with evaporating ice cloud being observed by the radar were examined. As Larkhill is not an operational station, there were only 18 such ascents available. Six of these were not used in the study. This was either because the MetUM did not have ice cloud present, even though the radar did, or the humidity gradient could not be accurately determined (to within 10\%) from some noisy sonde profiles. The sonde humidity gradients are plotted alongside the corresponding hourly model humidity gradients in figure 9. It can be seen that the MetUM consistently underestimates the humidity gradient beneath the evaporating ice cloud, with values of humidity gradient typically around a third of those observed by the sonde. The most likely explanation is that the numerics of the model are diffusive, so sharp gradients in humidity cannot be maintained within the evaporation zone. 

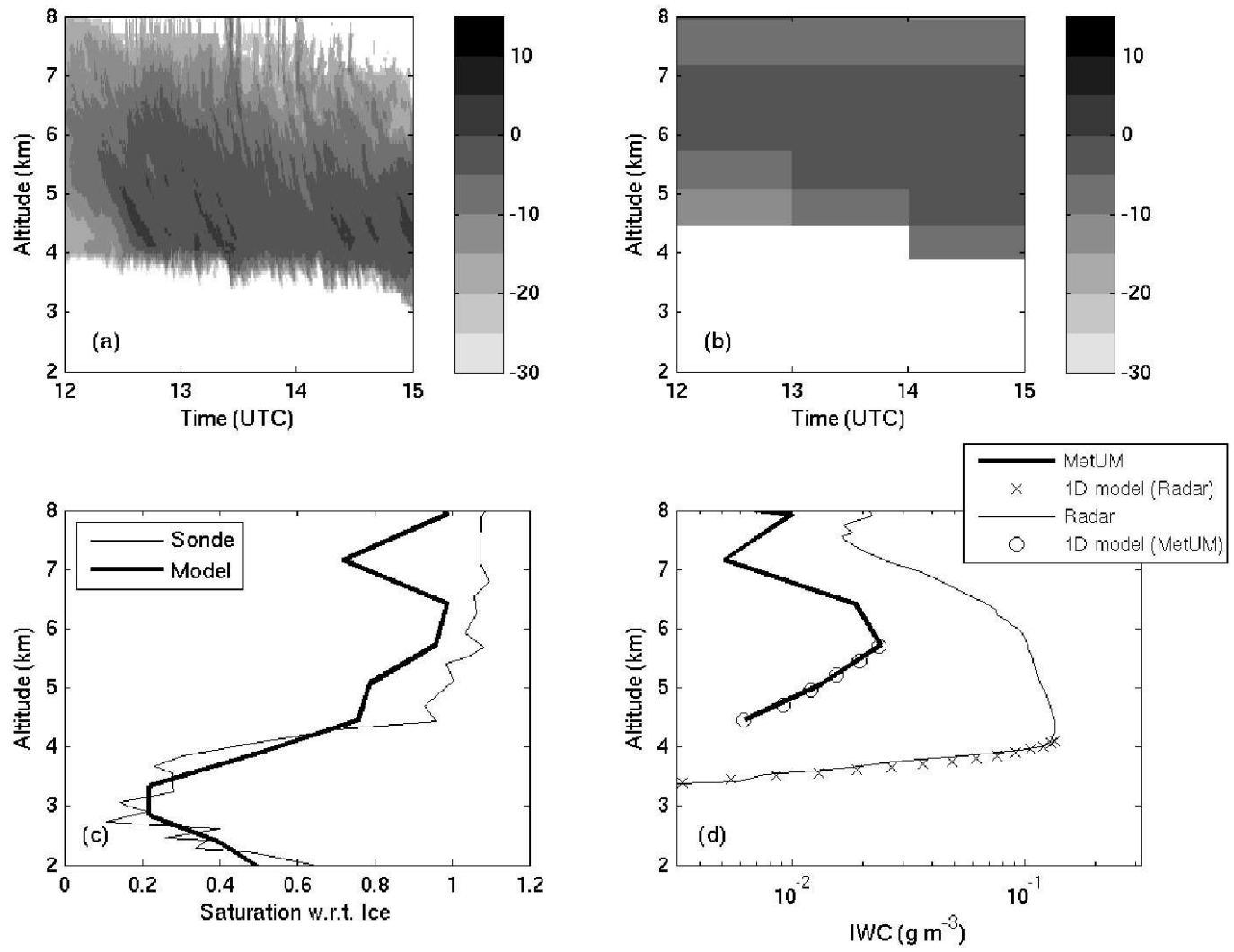

Figure 8. Analysed data from radar, MetUM and 13 UTC Larkhill radiosonde on 4 March 2004. (a) Observed radar reflectivity factor; (b) MetUM reflectivity factor, derived from MetUM IWC. (c) Radiosonde and MetUM humidity profiles at 13 UTC. (d) Ice water content at 13 UTC for MetUM, radar and using a 1D explicit microphysics MetUM (see section 5). Radar ice water content was calculated from reflectivity and MetUM temperature using equation 14 of Hogan et al. (2006).

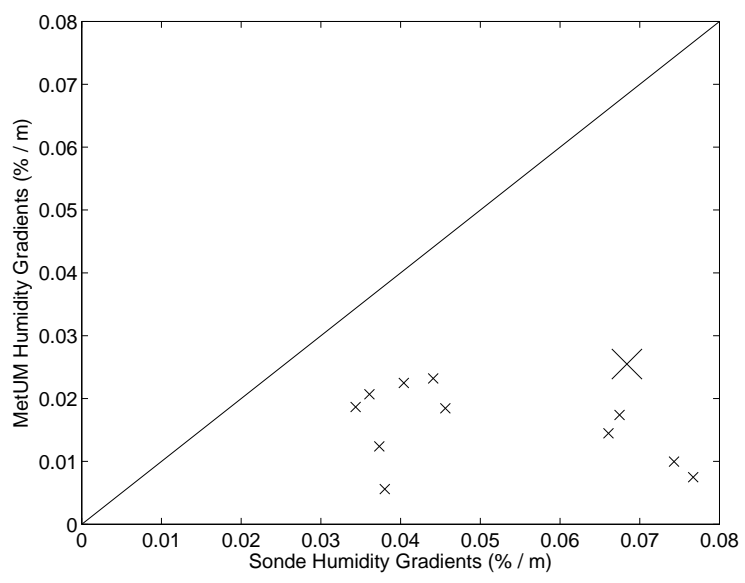

Figure 9. Sonde and Model Humidity gradients. The largest cross marks the data from 4 March 2004. The solid line is the line $y=x$.

\section{1D Explicit Microphysics Modelling}

In order to prove this humidity is the cause of the deep MetUM evaporation zone, it is necessary to carry out some simple 1D numerical model simulations to test the sensitivity of the sublimating regions to important prognostic variables carried in the MetUM. In addition, the 1D model allows radar measurements of ice water content, derived using the method of Hogan et al. (2006) and profiles of temperature, pressure and humidity from the nearby Larkhill radiosonde station to be used to simulate real evaporation cases. The 1D model is able to follow individual particles and give the number concentration and present size of a particle compared to its initial diameter. A complete description of the 1D model is given in appendix II.

5.1 A simple experiment to illustrate model performance

An initial experiment was set up for the 1D model, in which the humidity gradient was fixed at $0.06 \% \mathrm{~m}^{-1}$, with relative humidity decreasing linearly beneath the top of the evaporation zone. In the first run, the initial values of the other variables also remained fixed as follows: temperature $-20^{\circ} \mathrm{C}$, increasing adiabatically below the top of the evaporation zone; pressure $850 \mathrm{hpa}$, increasing with a scale height of $8 \mathrm{~km}$ and $D_{0}$ of $0.5 \mathrm{~mm}$ (which, using the temperature at the top of the evaporation zone means an equivalent IWC of $7.7 \times 10^{-3} \mathrm{~g} \mathrm{~m}^{-3}$ ). 

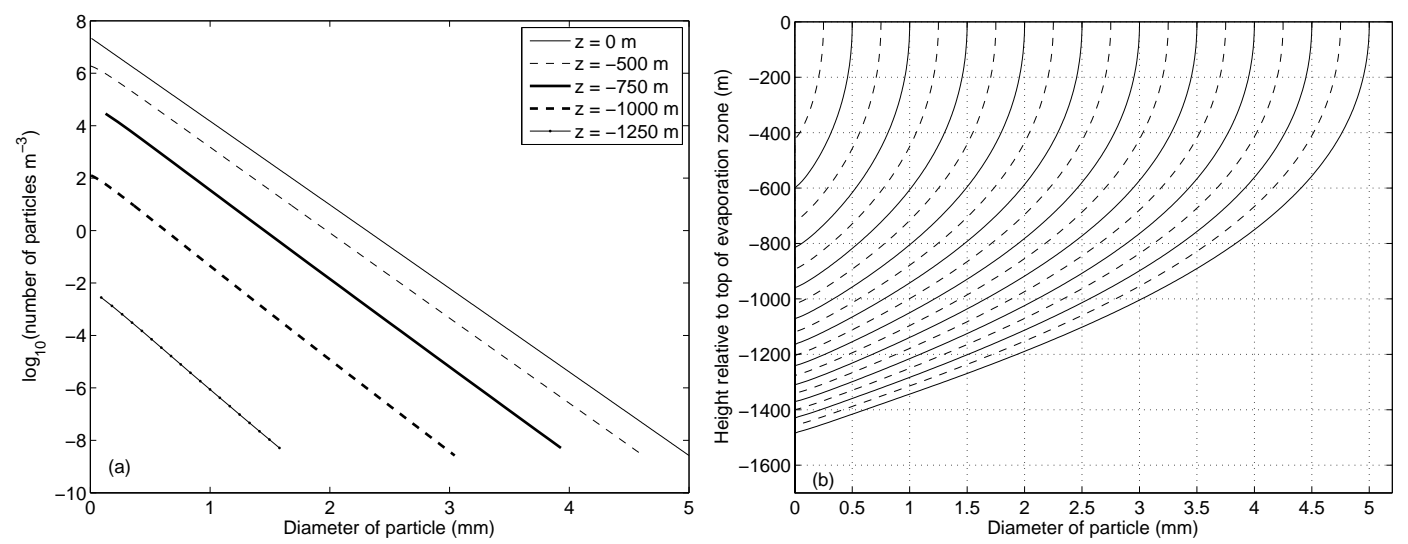

Figure 10. (a) $1 \mathrm{~d}$ model ice particle size distributions at the start of evaporation $(\mathrm{z}=0 \mathrm{~m})$ and at a range of heights below the top of the evaporation zone. (b) Size-height curves for a selection of ice particles, with diameters every $0.25 \mathrm{~mm}$ from 0.25 to $5 \mathrm{~mm}$ and showing survival distance for each particle. The 1D model produced an evaporation zone depth of $505 \mathrm{~m}$ for this run and the $5 \mathrm{~mm}$ particles survived as far as $1485 \mathrm{~m}$.

Figure 10 shows how the number concentration and particle size changes for different heights below the evaporation zone in the initial experiment. Figure 10(a) shows that the initial number concentration of $5 \mathrm{~mm}$ particles is less than 1 in $10^{8} \mathrm{~m}$ and hence the contribution of these particles to the ice water content will be very small, despite their size. At $500 \mathrm{~m}$ below the top of the evaporation zone, figure 10(b) shows that only particles with initial diameters greater than $0.375 \mathrm{~mm}$ will have survived and plot (a) shows that the number concentration of all particles has decreased substantially as the smaller particles evaporate. At $1 \mathrm{~km}$ below the top of the evaporation zone, the largest number concentration is 100 per cubic metre. Heymsfield and Donner (1990) suggest that all sublimation should occur within this distance and we can see that only a small number of large particles (initial diameters greater than $1.75 \mathrm{~mm}$ from plot (b)) exist within the model. Although the largest particles survive to 1485 $\mathrm{m}$, it is contribution of the smaller particles which leads to an evaporation zone of only 505 metres.

5.2 Evaporation Depth Sensitivity to Temperature, Pressure, Humidity and Initial Ice Water Content

A sensitivity study was then performed to see how the evaporation depth changed with relative humidity gradient and one of the other variables (IWC, temperature and pressure). To do this, a control experiment was created by using the same settings as the initial experiment, but altering the humidity gradient over a range of values from 0.001 to $0.08 \% \mathrm{~m}^{-1}$. Next, a set of four experiments were run for different combinations of the input variables to test the sensitivity of the model to various parameters as follows:

(i) Sensitivity to initial temperature. The simple numerical model was run exactly as the control run, but with the initial temperature being varied from $-30^{\circ} \mathrm{C}$ to $-5^{\circ} \mathrm{C}$. This range spans the profiles of temperature seen in the MetUM at the altitudes of ice cloud bases above Chilbolton, allowing for seasonal variations.

(ii) Sensitivity to initial IWC. The value of $D_{0}$ was altered within the model, from $0.25 \mathrm{~mm}$ to 1.5 $\mathrm{mm}$. This represented a change in IWC between 9 $\times 10^{-4} \mathrm{~g} \mathrm{~m}^{-3}$ and $0.21 \mathrm{~g} \mathrm{~m}^{-3}$ at this temperature, which is representative of the range of values observed over Chilbolton during the studies earlier in this paper. No changes were made to the ice water content by altering the number concentration of the particles, as in the simple numerical model it is assumed that all particles of the same size evaporate at the same rate and take the same distance to evaporate. Therefore increasing the number of particles of any given size would not have any effect on the evaporation zone depth.

(iii) Sensitivity to initial pressure. The model was run with variations made in initial pressure, ranging from $500 \mathrm{mb}$ to $1000 \mathrm{mb}$, but with the other parameters exactly as in the control run. The range of pressures used spanned the observed pressure levels at which evaporation started in the radiosonde profiles.

(iv) Sensitivity to temperature gradient. Lastly, we ran the model with constant temperature throughout the domain to see how this would affect the evaporation depth. To create this experiment, we took the control run and replaces the linear temperature gradient with an isothermal layer with temperature of $-20^{\circ} \mathrm{C}$.

The results of all four experiments are shown by the lines in figure 11. It can be seen that the sonde-and-radar derived evaporation zone depth decreases with increasing relative humidity gradient and that the MetUM data appears to be following the same curve as the radar data. Hence the two obey the same laws of physics. However, the MetUM has smaller humidity gradients, and a result, 


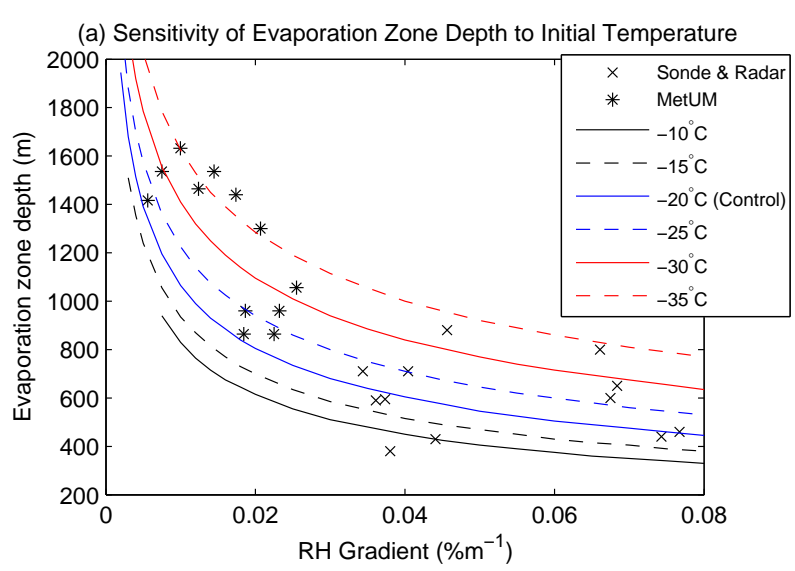

(b) Sensitivity of Evaporation Zone Depth to initial $\mathrm{D}_{0}$

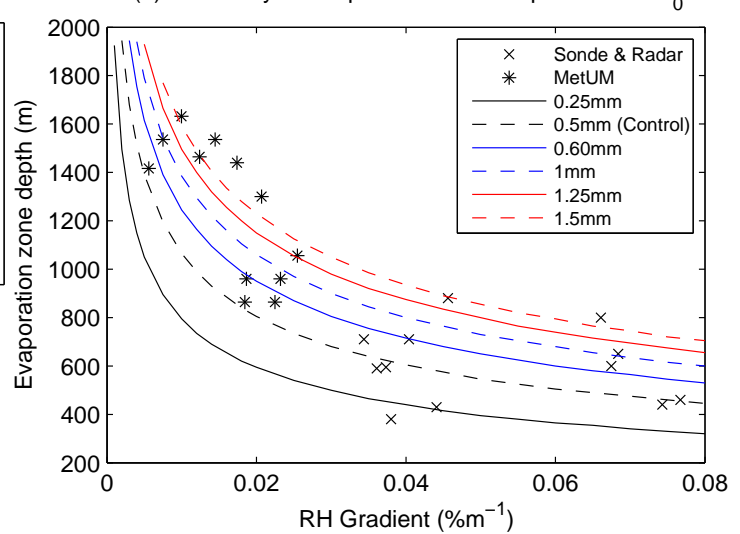

(c) Sensitivity of Evaporation Zone Depth to initial Pressure

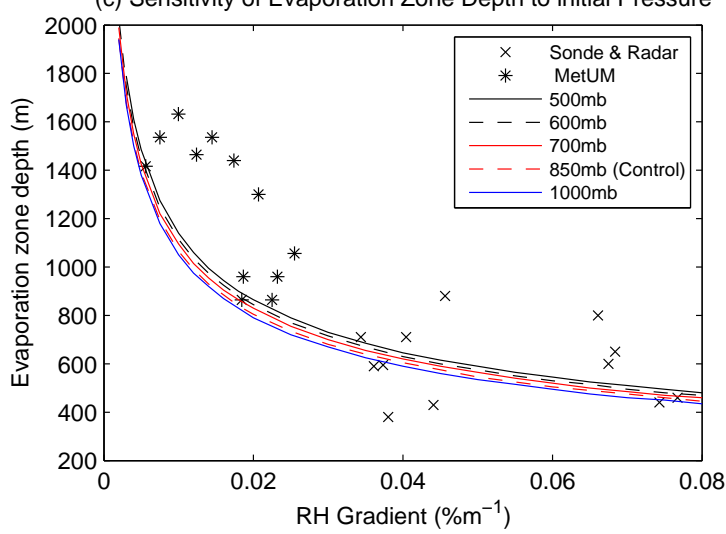

(d) Sensitivity of Evaporation Zone Depth to $d T / d z$

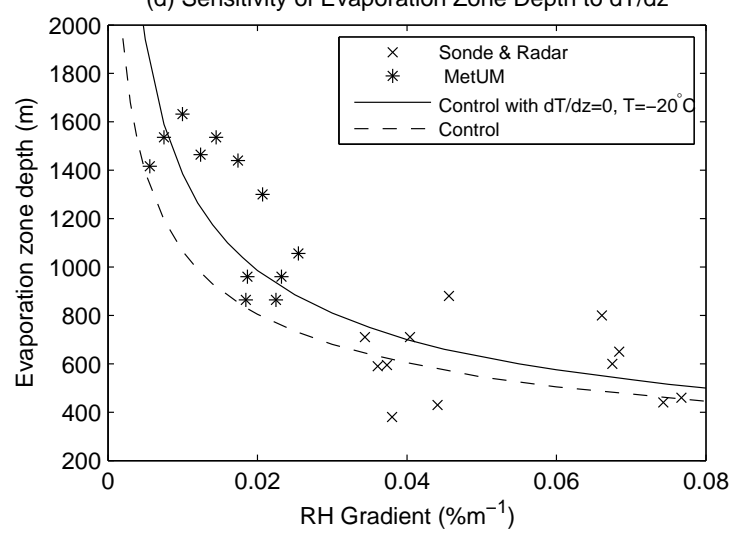

Figure 11. Changes in evaporation zone depth with changes in (a) initial temperature, (b) initial $D_{0}$, (C) initial pressure and (d) when the linear temperature gradient in the 1D model is replaced with an isothermal layer. The stars represent the points taken from the MetUM data and the crosses represent the corresponding observations from same cases as the MetUM data. In the observations, the evaporation zone depths from the radar data and humidity gradients from sonde measurements. Although the model was run on a domain of $6 \mathrm{~km}$, only realistic solutions (where the temperature remains below zero degrees Celsius) are shown.

the evaporation zones are deeper. This provides quite conclusive evidence that an incorrect humidity gradient is the cause of the deeper evaporation zone in the model.

From figure 11, we can also see that the evaporation depth decreases quite rapidly as humidity gradient increases, in all cases. Hence, the evaporation depth is most sensitive to the humidity gradient. It is worth noting that relative humidity can have some errors when measured from radiosondes. Ferrare et al. (1995) noted a systematic dry bias in Vaisala radiosonde measurements (like those used in this study) when compared to Raman lidar, of the order of 3-5\%. Heymsfield and Miloshevich (1995) found that the observed humidity from Vaisala radiosondes was sub-saturated when simultaneous crystal measurements showed pristine crystals growing in icesupersaturated measurements, hence suggesting that the radiosonde humidity had a dry-bias. Miloshevich et al. (2004) also noted the lags of radiosonde humidity sensors. For the Vaisala radiosondes, this lag varies from a couple of seconds at $-10^{\circ} \mathrm{C}$ to twenty seconds at $-35^{\circ} \mathrm{C}$, which is the range of temperatures ice was found to evaporate in this study. Despite these biases, relative humidity can be measured to within $5 \%$ and the humidity gradient derived from sondes is accurate enough to get humidity gradient to within $10 \%$, which is more than sufficient for this analysis.

Figure 11(a) shows that the sensitivity to evaporation zone temperature is also an important factor in determining evaporation zone depth. The temperature fields within the MetUM are accurate to within a couple of degrees Celsius and so this is not likely to be the cause of the deep evaporation zone in the MetUM, but nonetheless, any 1D model that wants to accurately measure evaporation depth scales must include a temperature gradient rather than assuming an isothermal layer. Figure 11(d) shows the effect of including a humidity gradient, but no temperature gradient in the 1D model. This isothermal layer means that although the relative humidity decreases within the profile, the specific humidity is much greater at each individual point in the profile. Since evaporation is sensitive to specific humidity, this means that deeper evaporation zones will occur. The overall conclusion from this study is that the variable controlling evaporation rate and evaporation depth is specific humidity and that whenever a gradient in relative humidity is present, a gradient in temperature should also be used to ensure accurate evaporation within the model. Previous studies (Hall and Pruppacher, 
1976; Harris, 1977) did not make this assumption. However, if we want to know what is causing the deep evaporation zone within the MetUM, we must deal with the sensitivity to each variable individually.

Figure 11(b) shows the effect of changing the value of $D_{0}$ on the evaporation depth, over a typical range of values. The results show that changing the value of $D_{0}$ has a large effect on the ice evaporation depth and therefore it is important that the model has a particle size and ice water content reasonably accurate, but if we examine figure 11(b), we can see that to cause a doubling in evaporation zone depth, the model's $D_{0}$ would have to be double the value seen in nature, which would mean an ice water content of about one order of magnitude larger, assuming the same total particle number and temperature. If such an error were present in the mean particle size, we would have seen a much larger radar reflectivity factor when we examined this in section 3.3.

Figure 11(c) shows the sensitivity to pressure variations within the 1D model. Generally pressure is represented accurately within the MetUM and as can be seen from the plot, evaporation depth is not sensitive to significant pressure changes. Changing pressure only changes the ventilation coefficient by a small amount and this is not enough to change the evaporation depth by more than a few metres and hence we can conclude that incorrect pressure is not a cause of a deep evaporation zone within the MetUM.

\subsection{Evaporation Depth Calculations Using Radiosonde Humidity and Temperature Profiles}

Having tested the 1D model with idealised profiles of temperature, relative humidity and pressure, the next step is to find out how well the model can represent the observed IWC profile when initialised with real sonde temperature, pressure and humidity profiles from radiosondes.

The 1D model was initiated with the sonde profiles used in section 4. In each case, the start of the evaporation was defined by examining the humidity profile and locating the sharpest drop in humidity closest to the height at which the radar data showed maximum values of IWC. In practise, it was not too difficult to pick subjectively the sharpest drop in humidity for each case. The top of the evaporation zone was defined as the maximum point in humidity immediately above the sharp drop in humidity. The 1D model was run on each of the 12 sonde cases, along with the corresponding MetUM data for these cases. The results for the 1D model in the case of 4 March 2004 are shown as black crosses (for the 1D model initialised with sonde and radar data) and black circles (for the 1D model initialised with MetUM data) in figure 8(d). It can be seen that the 1D model and radar profiles agreed through most of the evaporation zone. The radar data for this case show an almost constant cloud base with time and therefore the sonde data from the 13 UTC sonde was quite likely to be representative of the radar data above Chilbolton. Not all cases agree as well as this one, but it shows that the simple numerical model can produce an

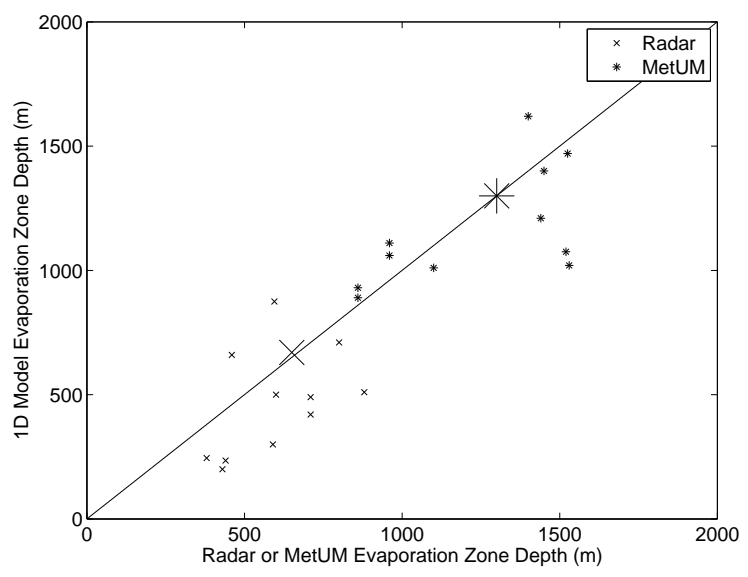

Figure 12. Scatter plot of evaporation depths for the simple numerical model using the humidity profiles generated for each of the twelve sonde (crosses) and model (circles) cases and the actual radar or MetUM evaporation depth. The solid line is the line $\mathrm{y}=\mathrm{x}$, and the largest symbols are from 4 March 2004.

accurate estimate of evaporation depth given a good sample of data. Similarly, the 1D model agrees almost exactly with the MetUM profile, proving that the input of humidity and temperature gives the same results whether they be interpolated on to a $5 \mathrm{~m}$ grid or when using the MetUM height grid.

The results for all 12 sonde cases used are shown in figure 12. This shows that the points generated for each of the twelve runs of the simple numerical model with radiosonde data and each of the twelve runs of the simple numerical model with MetUM data appear to lie approximately on the same line. When the 1D model is initiated with radar and sonde data, the results predict evaporation zone depths on the same scale as those observed by the radar. This implies that the MetUM has the correct evaporation physics, but the inputs of humidity into the MetUM are wrong, causing deeper evaporation zone depths within the MetUM.

It should also be noted that not all points lie perfectly on the straight line in figure 12. There is some scatter in both model and radar data which may be due to random measurement noise. This is particularly true for radarderived values of IWC. Hogan et al. (2006) shows that rms errors on radar-derived IWC are around $+50 \%$ to $-30 \%$ for temperatures between $-20^{\circ} \mathrm{C}$ and $-10^{\circ} \mathrm{C}$, but this rises to $+100 \%$ to $-50 \%$ at temperatures lower than $-40^{\circ} \mathrm{C}$. Also, the $1 \mathrm{D}$ model does not set its ice particle size distribution to the form of (1) after each time step; yet the MetUM does.

So far, all experiments with the MetUM have assumed that the capacitance of the particle, $C$, may be approximated by that of a sphere of diameter $\mathrm{D}$, i.e. $C=D / 2$. This assumption has been adopted for use in the simple numerical model. However, this should be relaxed in light of evidence (Field and Heymsfield, 2003; Westbrook et al., 2007) that aggregates are the dominant particle habit in thick non-precipitating ice clouds such as those studied in this paper. Numerical experiments by Westbrook et al. (2008) have shown that for aggregates, 
the value of capacitance is roughly half the value for spheres $(D / 4)$, which would lead to a reduction of the evaporation rate. This would imply that, for all else being equal, the evaporate zone depth would actually increase.

\section{Summary and Conclusions}

In this study, we have looked into the problem with ice sublimation depth scales when comparing NWP models to radar measurements that were noted by FH06 and Wilkinson (2007). The evaporation depth scales of ice particles have been shown previously by FH06 to impact on frontal evolution.

We have used the advantages of Doppler radar and radar simulation techniques to identify and reject many factors that were hypothesised to be the cause of the deep evaporation depth scale within the Met Office model. Particle terminal velocity was found to be $30 \%$ too small within the model and would have to be significantly increased to cause the problem. There is no evidence that turbulence is the cause of the deep evaporation zone either. Changing the particle density does not feedback or alter the particle terminal velocity parametrization within the MetUM. However, sonde results show that humidity drops off rapidly within the sublimating layer; this is not represented correctly in the model.

Using a 1D explicit microphysics model, it can be seen that the sublimation depth is most sensitive to humidity and temperature. When real life evaporation cases are simulated with sonde and radar inputs, the simple numerical model shows gives an accurate representation of the evaporation zone depth.

In this study, for space considerations we have only considered the MetUM despite having shown that problems with evaporation zone depth extend to all models in the Cloudnet programme, shown in table I. However, further work could be undertaken to assess how each parametrization scheme represents the humidity gradient. Possible other further work could consider the sensitivity to different particle shapes (the MetUM and 1D model assume aggregates; would the MetUM perform better with a different shape type?)

\section{Acknowledgements}

Thanks to Ewan O'Connor for coding of the Cloudnet processing algorithms and to the Rutherford Appleton Laboratory for maintaining the instruments at Chilbolton and for the provision of the original data. Thanks go to the Met Office for providing the computing resources necessary to finish this manuscript. We would also like to acknowledge Alan Blyth for valuable comments provided on this work. The first author was supported by a NERC studentship.

\section{Appendix I: Radar Simulation}

The ice parametrization scheme used in the Met Office Unified Model is detailed in full in Wilson and Ballard
(1999). The model carries IWC as a prognostic variable, using an exponential ice particle distribution as follows:

$$
N(D)=N_{0} e^{-0.122 T} e^{-\Lambda D}=N(T) e^{-\Lambda D}
$$

where $N(D)$, the number concentration per unit diameter is a function of $D$, the particle diameter in $\mathrm{m}$, temperature, $T$ in ${ }^{\circ} \mathrm{C}$ and $\Lambda=\frac{3.67}{D_{0}}$, where $D_{0}$ is the equivolumetric median diameter. The MetUM assumes that $N_{0}=2 \times 10^{6}$ $\mathrm{m}^{-4}$ and the mass of an ice particle is Parametrized as

$$
m(D)=a D^{b}
$$

where $a=0.069 \mathrm{~kg} \mathrm{~m}^{-2}$ and $b=2.0$. Using this equation, the density of the particles in the MetUM can be defined as

$$
\rho=0.13 D^{-1}
$$

where $\rho$ is the particle density in $\mathrm{kg} \mathrm{m}^{-3}$ and $D$ is in $\mathrm{m}$. This equation is similar in form to that proposed by Brown and Francis (1995): $\rho=0.07 D^{-1.1}, \mathrm{~g} \mathrm{~cm}^{-3}$ but given the difference in units, there is a factor of four difference in the resulting density for typical particle sizes. In this simulation, particle density is capped at the density of solid ice, which prevents the formation of superdense ice. The MetUM parametrization for the mass of ice is also given as a function of $D$. Thus, ice water content (IWC) can be expressed as

$$
\mathrm{IWC}=\int_{0}^{\infty} N(D) m(D) d D
$$

Equations $1 \& 3$ can be used to simulate the radar reflectivity, $Z$ and Doppler Velocity of the crystals, $V_{\text {Dop }}$, as follows (after e.g. Brown et al., 1995; O'Connor et al., 2005):

$$
\begin{aligned}
Z & =\int_{0}^{\infty} \frac{|K|^{2}}{0.93} \gamma(D) N(D) D^{6} d D \\
V_{\text {Dop }} & =\frac{\int_{0}^{\infty}\left|K_{i c e}\right|^{2} N(D) \gamma(D) v(D) D^{6} d D}{\int_{0}^{\infty}|K|^{2} N(D) \gamma(D) D^{6} d D} .
\end{aligned}
$$

The term $\gamma$ in (5) and (6) represents the Mie to Rayleigh ratio and is a function of diameter, with values ranging from 0 to $1 .\left|K_{i c e}\right|^{2}$ is the dielectric factor of the ice particle,which is approximately proportional to its density squared. The value of 0.93 is the dielectric factor for liquid water at $\mathrm{cm}$ wavelengths.

The term $v(D)$ in (6) refers to the fall-speed of an ice particle of diameter $D$, Parametrized by Wilson and Ballard (1999) as

$$
v\left(D, \rho_{a}\right)=\alpha D^{\beta}\left(\frac{\rho_{0}}{\rho_{a}}\right)^{0.4}
$$

where $\alpha=25.2 \mathrm{~m}^{0.47} \mathrm{~s}^{-1}$ and $\beta=0.527$. The air density, $\rho_{a}$ is calculated from the MetUM's pressure and temperature fields, while $\rho_{0}$ is a reference density of $1 \mathrm{~kg} \mathrm{~m}^{-3}$. 
The method used to calculate $Z$ and $V_{\text {Dop }}$ from IWC is straightforward. At each grid box, the MetUM value of IWC is calculated from the ice water mixing ratio $\left(q_{i}\right)$ according to

$$
\mathrm{IWC}=\frac{p q_{i}}{R T},
$$

where $p$ is the pressure and $R$ is the gas constant for dry air. Using values of $D$ from 0 to $20 \mathrm{~mm}$, which when given with (1) represent the full spectrum of ice particles observed in nature,(4), (5) and (6) are used to calculate values of IWC, $Z$ and $V_{\text {Dop }}$ for values of $D_{0}$ between 0 and $5 \mathrm{~mm}$, and for a temperature of $0^{\circ} \mathrm{C}$. There is some modification to both $Z$ and $V_{\text {Dop }}$ when Mie scattering is assumed. Mie scattering affects the calculation of $Z$ at higher temperatures. Analytical solutions are available to relate $Z$ to IWC for Rayleigh scattering; $Z$ is roughly proportional to IWC ${ }^{5 / 3}$ (Hogan et al., 2006) and $V_{\text {Dop }}$ is roughly proportional to $\Lambda^{0.527}$, but when Mie scattering is included, only numerical solutions are possible.

In order to calculate $Z$ and $V_{\text {Dop }}$ from the MetUM without needing $2 \mathrm{D}$ interpolation, the values of IWC for the temperature in the MetUM data are found by scaling to the equivalent value of IWC at $0^{\circ} \mathrm{C}\left(\mathrm{IWC}_{T=0}\right)$, using a scaling factor, $s=\exp (-0.122 T)$, where $T$ is in ${ }^{\circ} \mathrm{C}$. Since the radar reflectivity factor is temperature dependent, the value of $Z_{T=0}$ must be converted to a value of $Z$ by $s$. Since (6) has the $N(D)$ terms on both the top and bottom of the equation is independent of temperature and hence the $V_{\text {Dop }}$ value does not need to be scaled by the temperature factor.

\section{Appendix II: Description of the explicit microphysics model}

The 1D simple numerical model is run with a vertical grid with a $5 \mathrm{~m}$ vertical resolution and a $6 \mathrm{~km}$ domain. The effects of horizontal and vertical advection are neglected, so that the only processes acting are the fall and evaporation of ice particles. The explicit microphysics model assumes a spectrum of particles with the smallest diameter being $0.01 \mathrm{~mm}$ and with diameters increasing by 0.01 $\mathrm{mm}$ until we reach the maximum size of $20.0 \mathrm{~mm}$. In each numerical simulation, particles with varying diameters are allowed to fall from the top of the column and evaporate. The only processes acting were the evaporation of ice and the fall of the particles; horizontal and vertical advection were not included.

The temperature profile was set to be dry adiabatic with different initial temperatures at the top of the domain. The top of the domain marks the point where the evaporation started, or $z_{a d j}=0$. Unrealistic runs, where the temperature increased above $273 \mathrm{~K}$ and therefore the ice would melt, rather than evaporate were removed from the study. The profile of pressure decreased with height using a simple exponential with a scale height of $8 \mathrm{~km}$, and a user-defined initial pressure.

The initial value of IWC is a function of temperature and the particle median diameter $\left(D_{0}\right)$ as expressed in (4). However, once the temperature at the top of the profile is nown, (1) and (4) can be inverted to obtain $\mathrm{D}_{0}$. So, the user can decide on a particular IWC to use at the top of the profile. This is then converted to give the corresponding value of $D_{0}$ at that temperature, which the model then uses to set up the particle size distribution as given in (1). The maximum allowed value of $\mathrm{D}_{0}$ was $5.0 \mathrm{~mm}$, which is equivalent to a maximum ice water content of $0.70 \mathrm{~g} \mathrm{~m}^{-3}$ (assuming a temperature of $0^{\circ} \mathrm{C}$ ), which is far greater than any ice water content observed in this study.

In the initial experiments (sections 5.1 and 5.2), a simple linear humidity gradient was used. In all cases, the humidity was set as $100 \%$ at the top of the domain and was not allowed to fall below $20 \%$ at any point in the profile.

The evaporation rate equation is given by Wilson and Ballard (1999), following the work of Mason (1953):

$$
\frac{d m}{d t}=\frac{4 \pi C\left(S_{i}-1\right) F}{\left(\frac{L_{s}}{R T}-1\right) \frac{L_{s}}{k_{a} T}+\frac{R T}{X e_{\text {satice }}}},
$$

where $m$ is the mass of an individual ice particle, $t$ is time, $C$ is the capacitance of the particle, which for spheres is $\frac{D}{2}$, where $D$ is the particle diameter, $S_{i}$ is the saturation ratio $\left(\frac{\mathrm{RH}}{100}\right), T$ is the temperature $(\mathrm{K}), R$ is the gas constant for water vapour, $L_{s}$ is the latent heat of sublimation of ice to vapour, $X$ is the diffusivity of vapour, $e_{\text {satice }}$ is the saturation vapour pressure with respect to ice and $k_{a}$ is the thermal conductivity of air. $F$ is the ventilation coefficient, given for spheres as

$$
F=0.65+0.44 \mathrm{Sc}^{1 / 3} \operatorname{Re}^{1 / 2},
$$

where Sc is the Schmidt number, equal to 0.6 and Re is the Reynolds number $\left(v(D) \rho_{a} D\right) / \mu$, where $\rho_{a}$ is the air density, $v(D)$ is the fall velocity of the crystal and $\mu$ is the dynamic viscosity of the air. The physical meaning of $F$ is the effect of a moving airstream passing the evaporating ice particle and hence increasing the rate of evaporation (Mason, 1971; Pruppacher and Klett, 1997). The more turbulent the air, the higher the Reynolds number in (10) and the faster the evaporation rate. The ventilation for the largest particles approaches 10, hence the rate of evaporation for these largest particles is much greater. Since ice water content is dominated by these largest particles, it is important that the ventilation coefficient is represented accurately to ensure the correct evaporation depth occurs.

The terms $L_{s}, X, e_{\text {satice }}, k_{a}$ are functions of temperature and pressure. With the exception of $e_{\text {satice }}$, all these variables are weak functions of temperature and pressure. The capacitance, $C$ is a function of diameter, $D$ and $F$ is a function of $D$, temperature and pressure. Thus, the evaporation equation can be expressed as a simplified function of just a few variables, as follows:

$$
\frac{d m}{d t}=f(D, \mathrm{RH}, T, p)
$$

The mass of an ice particle $(\mathrm{kg})$ and its fall speed $(\mathrm{m}$ $\mathrm{s}^{-1}$ ) in the MetUM is given as a function of its diameter in metres as follows:

$$
m(D)=0.069 D^{2},
$$




$$
v(D)=25.2 D^{0.527}
$$

These equations are based on Cox (1988) and Locatelli and Hobbs (1974). The values used in (12) were selected by Cox (1988) to give a sensible variation of particle density with size. This results in a mass and density relation that is roughly four times that suggested by the Brown and Francis (1995) relationship. This study retained the MetUM values to try and make the 1D model as close to the MetUM parametrization scheme as possible. The values used in (13) are larger than those given by Cox (1988), who used $v(D)=16.8 D^{0.527}$.

In order to obtain the distance an individual particle falls before it completely evaporates, we must first convert (9) to an expression for the change in diameter of a particle over time and then use the fall speed to convert this to a fall distance $(z)$. This can be done using (12) and (13) and the chain rule. Once this information is known, the survival distance of an individual particle can be calculated numerically by integration. The number concentration of ice particles in the MetUM is given as in (1). The MetUM resets the distribution back to the form in (1) at every vertical step, but in this explicit model, the smallest particles evaporate first. As the MetUM resets the distribution to its initial form, it automatically adds more small particles in place of a few large ones. Since evaporation depth depends on ice water content, which is proportional to the cube of diameter, this will mean that in the Met Office scheme the IWC will artificially reduce and the evaporation zone depth will decrease. However, the MetUM vertical resolution at ice cloud altitudes ranges from $500 \mathrm{~m}$ to $750 \mathrm{~m}$, so this resetting process will have little effect on the evaporation depth, if the correct humidity gradient were maintained.

\section{References}

Arking, A. (1991). The radiative effects of clouds and their impact on climate. Bull. Amer. Meteorol. Soc., 72, 795-813.

Bouniol, D., Illingworth, A. J., and Hogan, R. J. (2003). Deriving turbulent kinetic energy dissipation rate within clouds using ground based $94 \mathrm{GHz}$ radar. In Proc. 31 st AMS Conference on Radar Meteorology, volume 1, pages 193-196, Seattle, USA.

Brown, P. R. A. and Francis, P. N. (1995). Improved measurements of the ice water content in cirrus using a total-water probe. J. Atmos. Ocean. Technol., 12, 410414.

Brown, P. R. A., Illingworth, A. J., Heymsfield, A. J., McFarquhar, G. M., Browning, K. A., and Gosset, M. (1995). The role of spaceborne millimeter-wave radar in the global monitoring of ice cloud. J. Appl. Meteorol., 34, 2346-2366.

Clough, S. A. and Franks, R. A. A. (1991). The evaporation of frontal and other stratiform precipitation. Q.J. R. Meteorol. Soc., 117, 1057-1080.
Clough, S. A., Lean, H. W., Roberts, N. M., and Forbes, R. M. (2000). Dynamical effects of ice sublimation in a frontal wave. Q. J. R. Meteorol. Soc., 126, 2405-2434.

Cox, G. P. (1988). Modelling precipitation in frontal rainbands. Q. J. R. Meteorol. Soc., 114, 115-127.

Deng, M. and Mace, G. C. (2008). Cirrus cloud microphysical properties and air motion statistics using cloud radar Doppler moments: Water content, particle size, and sedimentation relationships. Geophys. Res. Lett., 35, L17808, doi:10.1029/2008GL035054.

Ferrare, R., Melfi, S., Whiteman, D., Evans, K. D., Schmidlin, F. J., and Starr, D. O. (1995). A comparison of water vapour measurements made by Raman lidar and radiosondes. J. Atmos. Ocean. Technol., 12, 1177-1195.

Field, P. R. and Heymsfield, A. J. (2003). Aggregation and scaling of ice crystal ize distributions. J. Atmos. Sci., 60, 544-560.

Forbes, R. M. and Hogan, R. J. (2006). Observations of the depth of ice particle evaporation beneath frontal cloud to improve NWP modelling. Q. J. R. Meteorol. Soc., 132, 865-883.

Hall, W. D. and Pruppacher, H. R. (1976). The survival of ice particles falling from cirrus clouds in subsaturated air. J. Atmos. Sci., 33, 1995-2006.

Harris, F. I. (1977). The effects of evaporation at the base of ice precipitation layers: Theory and radar observations. J. Atmos. Sci., 34, 651-672.

Heymsfield, A. J. and Donner, L. J. (1990). A scheme for parameterizing ice-cloud water content in general circulation models. J. Atmos. Sci., 47(15), 1865-1877.

Heymsfield, A. J. and Miloshevich, L. M. (1995). Relative humidity and temperature influences on cirrus formation and evolution. J. Atmos. Sci., 52, 4302-4326.

Hogan, R. J., Bouniol, D., Ladd, D. N., O'Connor, E. J., and Illingworth, A. J. (2003a). Absolute calibration of 94/95-GHz radars using rain. J. Atmos. Ocean. Technol., 20, 572-580.

Hogan, R. J., Francis, P. N., Flentje, H., Illingworth, A. J., Quante, M., and Pelon, J. (2003b). Characteristics of mixed-phase clouds. I: Lidar, radar and aircraft observations from CLARE'98. Q. J. R. Meteorol. Soc., 129, 2089-2116.

Hogan, R. J., Mittermaier, M. P., and Illingworth, A. J. (2006). The retrieval of ice water content from radar reflectivity factor and temperature and its use in evaluating a mesoscale model. J. Appl. Meteorol. Climatol., 45, 301-317. 
Illingworth, A. J., Hogan, R. J., O’Connor, E. J., Bouniol, D., Brooks, M. E., Delanoë, J., Donovan, D. P., Eastment, J. D., Gaussiat, N., Goddard, J. W. F., Haeffelin, M., Klein, H., Baltink, O., Krasnov, O. A., Pelon, J., Piriou, J.-M., Protat, A., Russchenberg, H. W. J., Seifert, A., Tompkins, A. M., van Zadelhoff, G. J., Vinit, F., Willén, U., Wilson, D. R., and Wrench, C. L. (2007). Cloudnet-Continuous evaluation of cloud profiles in seven operational models using ground-based observations. Bull. Amer. Meteorol. Soc., 88, 883-898.

Lhermitte, R. M. (1990). Attenuation and scattering of millimeter wavelength radiation by clouds and precipitation. J. Atmos. Ocean. Technol., 7, 464-479.

Locatelli, J. D. and Hobbs, P. V. (1974). Fall speeds and masses of solid precipitation particles. J. Geophys. Res., 79, 2185-2197.

Lohmann, U. and Roeckner, E. (1995). Influence of cirrus cloud radiative forcing on climate and climate sensitivity in a general circulation model. J. Geophys. Res., 100, 16305-16324.

Mason, B. J. (1953). The growth of ice crystals in a supercooled water cloud. Q. J. R. Meteorol. Soc., 79, 104-111.

Mason, B. J. (1971). The Physics of Clouds. Oxford University Press, 2nd edition.

Miloshevich, L. M., Paukkunen, A., Vömel, H., and Oltmans, S. J. (2004). Development and validation of a time-lag correction for vaisala radiosonde humidity measurements. J. Atmos. Ocean. Technol., 21, 13051327.

O'Connor, E. J., Hogan, R. J., and Illingworth, A. J. (2005). Retrieving stratocumulus drizzle parameters using Doppler radar and lidar. J. Appl. Meteorol., 44, 14-27.

Pruppacher, H. R. and Klett, J. D. (1997). Microphysics of Clouds and Precipitation. Kluwer, Dordrecht, 2nd edition.

Quante, M. (2004). The role of clouds in the climate system. J. Phys. IV France, 121, 61-86.

Senior, C. A. and Mitchell, J. F. B. (1993). Carbon dioxide and climate: The impact of cloud paramterization. $J$. Climate, 6, 393-418.

Stephens, G. L., Tsay, S. C., Stackhouse Jr, P. W., and Flatau, P. (1990). The relevance of the microphysical and radiative properaties of cirrus clouds to climate and climate feedback. J. Atmos. Sci., 47, 1742-1753.

Westbrook, C. D., Hogan, R. J., Illingworth, A. J., and O'Connor, E. J. (2007). Theory and observations of ice particle evolution in cirrus using Doppler radar: Evidence for aggregation. Geophys. Res. Lett., 34, L02824, doi:10.1029/2006GL027863.
Westbrook, C. D., Hogan, R. J., and Illingworth, A. J. (2008). The capacitance of pristine ice crystals and aggregate snowflakes. J. Atmos. Sci., 65, 206-219.

Wilkinson, J. M. (2007). Evaluating Numerical Model Cloud Parameterizations using Radar and Lidar Simulation. Ph.D. thesis, Dept. Meteorology, University of Reading.

Wilson, D. R. and Ballard, S. P. (1999). A microphysically based precipitation scheme for the UK Meteorological Office Unified Model. Q. J. R. Meteorol. Soc., 125, 1607-1636. 